\title{
LA PRESÈNCIA DE LES UNITATS FRASEOLÒGIQUES EN JARDÍ VORA EL MAR, DE MERCÈ RODOREDA I LES VARIACIONS DE LA TRADUCCIÓ CASTELLANA
}

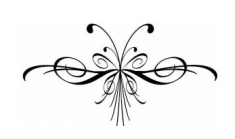

TRINIDAD ESCUDERO ALCAMÍ

Resum: Com a conseqüència del punt de vista narratiu escollit per Mercè Rodoreda, Jardí vora el mar (1967) és, sens dubte, l'obra amb més força fraseològica de l'autora. Aquest fet, inevitablement, hagué de complicar la tasca de traduir la novel·la al castellà a Joan Francesc Vidal i Jové, traducció que va ser publicada el 1975 per l'editorial Planeta amb el títol Jardín junto al mar. Donada l'escassa atenció que la crítica especialitzada ha prestat a aquesta obra i la mancança d'estudis que analitzen l'ús que Mercè Rodoreda fa de la llengua a les seues obres, en aquest article, ens plantegem dos objectius: d'una banda, analitzar l'ús que Mercè Rodoreda fa de les unitats fraseològiques a la novel-la; i de l'altra, comprovar quina ha estat la variació fraseològica duta a terme en la traducció al castellà de l'obra.

Paraules clau: Mercè Rodoreda; Jardí vora el mar; fraseologia; traducció.

\begin{abstract}
Because of the narrative point of view chosen by Mercè Rodoreda, Jardí vora el mar (1967) is, undoubtedly, the work with more phraseological force written by the author. This fact inevitably had to complicate the task of translating the novel into Spanish for Joan Francesc Vidal i Jové, whose translation was published by Planeta in 1975 titled Jardín junto al mar. Given the scant attention that the critics have paid to this novel and the lack of studies examining the use that Mercè Rodoreda makes of the language in her novels, in this article, we consider two objectives: firstly, to analyse how Mercè Rodoreda uses phraseological units in the novel; and on the other, which has been the phrasal variation held in the Spanish translation of this work.
\end{abstract}

Keywords: Mercè Rodoreda; Jardí vora el mar; phraseology; translation. 
$\mathrm{M}$ ercè Rodoreda, com tots sabem, és una dels autors catalans més traduïts a d'altres llengües. De fet, a partir de les dades recollides per la Fundació Mercè Rodoreda, l'autora "ha estat traduïda a trenta-tres llengües per seixanta-cinc traductors que han produït noranta-set traduccions en forma de llibre" (MALLAFRÈ 2010, p.69). A més, l'estudiós especificava que l'obra més traduïda de l'autora, en alguns casos més d'una vegada a la mateixa llengua, era La plaça del Diamant, seguida de Mirall Trencat, Aloma, El carrer de les Camèlies i La mort i la primavera, per aquest ordre. En concret, la novel-la que ara ens ocupa, Jardí vora el Mar, publicada el 1967, compta fins el moment amb tres traduccions: la primera, al castellà, va ser duta a terme per Joan Francesc Vidal i Jové el 1975 amb el títol Jardín junto al mar i publicada per l'editorial Planeta; la segona, a l'eslovac, va ser realitzada per Elena Rackova el 1979 amb el títol Záhrada pri mori i publicada per l'editoral SPKK i, finalment, el 1990, Clara Romanò la va traduir a l'italià amb el títol Il giardino sul mare que va ser publicada per l'editorial La Tartatuga.

A simple vista, crida l'atenció l'escassetat de traduccions existents d'aquesta obra en comparació amb la resta de novel-les de l'autora. Diverses podrien ser les motivacions que explicarien el per què d'aquesta evidència ${ }^{1}$, tot i això, considerem que una hi predomina per damunt de la resta: l'escassa atenció que Jardí vora el mar ha rebut per part de la crítica especialitzada. De fet, "la història de Jardí vora el mar és la història d'una novel·la eclipsada” (PORTA, 2013 p.215), eclipsada per altres obres mestres de l'autora que li han fet ombra; per una crítica, que massa sovint ha centrat les seues anàlisis exclusivament en el jardí com a espai central de la novel·la o han qualificat l'obra com una novel-la de crisi (ARNAU, 1979, p.207). Aquest darrer fet ens pot resultar especialment significatiu si tenim en compte que l'estudiosa Carme Arnau va dur a terme aquesta afirmació en el primer estudi que analitzava amb profunditat l'obra rodorediana. Finalment, com es pot llegir a l'epistolari entre Rodoreda i el seu editor, Joan Sales (RODOREDA/SALES, 2008, p.319), la novel·la va ser eclipsada, fins i tot, per l'estratègia de llançament planificada per aquests, ja que decidiren postergar la publicació de la novel-la, des de Sant Jordi fins a l'estiu, per no desviar l'atenció de La plaça del Diamant i d'El Carrer de les Camèlies que, en aquell moment, encara ocupaven llocs destacats als aparadors.

Dins d'aquesta escassa atenció que Jardí vora el mar ha rebut per part de la crítica especialitzada, considerem que hi ha un aspecte essencial de la novel-la que encara no ha estat analitzat d'una forma detallada: el punt de vista narratiu que escull l'autora a la novel-la i les implicacions lingüístiques que comporta. De tota manera, aquest fet no ens pot resultar sorprenent si tenim en compte que, en relació a les diferents perspectives des de les quals s'ha analitzat l'obra de Rodoreda, "els articles que es basen en una anàlisi lingüística són escassos però interessants" (MENCOS, 2003, p.14). El punt de vista escollit està basat en la tècnica del behavorisme, ja que Rodoreda tria com a focus de la narració el personatge del jardiner, un personatge secundari que ens narra la història com un mer observador de lluny que, evidentment, no pot saber-ho tot. Per tal de completar la història, Rodoreda se servirà de tot allò que el servei narra al jardiner, però ens ho farà saber a través de la veu del narrador.

\footnotetext{
${ }^{1}$ Indiquem entre parèntesi el nombre de traduccions completes amb què compten la resta de novel-les de Mercè Rodoreda, basant-nos en les dades actuals de la Fundació Mercè Rodoreda: Aloma (8), El carrer de les Camèlies (8), Isabel i Maria (2), La mort i la primavera (7), La plaça del Diamant (40), Mirall Trencat (18) i Quanta, quanta guerra... (5).
} 
Així, és el narrador qui reuneix finalment tots aquests fragments i ens narra la història bé perquè ho ha vist o bé perquè li ho han contat.

Però per què diem que l'aplicació d'aquesta tècnica narrativa està plenament relacionada amb l'ús que Rodoreda fa de la llengua a la novel·la? Perquè el fet que Rodoreda trie el jardiner $i$, en segon terme, el món del servei en general com a narradors directes $\mathrm{i}$ indirectes de la història ha de condicionar necessàriament el model de llengua emprat en la narració, per tal que el resultat siga versemblant. Aquesta versemblança narratològica només es pot aconseguir a la novel·la amb un model de llengua col-loquial i una autora de l'alçada de Rodoreda se n'adona i en fa ús. Així, "Rodoreda retrata magistralment aquest món del servei i el dota d'un llenguatge col-loquial —realista_ que és un dels millors encerts d'estil. La seua visió de la vida és simple, i utilitzen constantment frases fetes i expressions populars" (PORTA, 2013, p.226).

Com abastament sabem, les unitats fraseològiques són un dels elements lingüístics que presenten més resistència a la traducció. És per això que en aquest article analitzarem, d'una banda, l'ús que Mercè Rodoreda fa de les unitats fraseològiques a la novel·la; i de l'altra, comprovarem quina ha estat la variació fraseològica duta a terme en la traducció al castellà de l'obra. El nostre objectiu passa per contribuir a la creació de diferents diccionaris fraseològics de diversos autors catalans, cosa que károly Morvay va defensar en el Tretzè Col-loqui Internacional de Llengua i Literatura Catalana l'any 2003. Per a l'estudiós, l'elaboració d'aquests diccionaris fraseològics no sols serviria per a recollir la fraseologia d'una obra o de diferents obres d’un autor, sinó que serviria també "com a base sòlida per a investigacions sobre la fraseologia de la llengua literària del segle XX” (MORVAY, 2003, p.406) i com a ajuda per a l'ensenyament del català i per a la traducció d’obres catalanes.

Com hem esmentat abans, el traductor al castellà de Jardí vora el mar va ser Joan Francesc Vidal i Jové. Si bé aquest traductor es va dedicar principalment a traduir al castellà les obres de diversos autors catalans i francesos, entre elles Aloma i Jardí vora el mar de Mercè Rodoreda el 1971 i el 1975 respectivament, hi ha una tasca com a traductor que, a partir de l'any 2006, gràcies a l'estudi d'Alberto Lázaro, va refermar la seua posició en el mapa de la traductologia: el fet d'haver traduït per primera vegada l'Ulisses de Joyce al català l'any 1966 per a l'editorial AHR, tot i que, a dia d'avui, aquesta traducció encara resta inèdita i arxivada a l'Archivo General de la Administración de Alcalá de Henares².

Considerem essencial, en aquest punt, esmentar quatre apunts biogràfics de Joan Francesc Vidal i Jové, ja que, sota la nostra opinió, aquestes dades ens podran donar informació sobre quina mena de traductor era i de quina manera es podria haver enfrontat a la traducció de Jardí vora el mar. Joan Francesc Vidal i Jové va nàixer a Manresa l'any 1899 i va morir a Newcastle el 1978. Com explica Alberto Lázaro

\footnotetext{
${ }^{2}$ Tal i com Teresa Iribarren explica al Diccionari de la Traducció Catalana (2011: 581) a partir de la investigació d’Alberto Lázaro, aquesta traducció de l'Ulisses, la primera traducció completa de l’obra a l'Estat Espanyol, resta encara inèdita i dipositada a l'Archivo General de la Administración de Alcalá de Henares, tot i que va obtenir el vistiplau de la censura. Per a Alberto Lázaro (2008), l'aprovació per part de la censura possiblement es deguera al fet que el director i fundador d'AHR, Alfredo Herrero Romero, sentia una afinitat ideològica amb el règim franquista i també al fet que ja existia una edició anterior en espanyol que comptava amb l'aprovació d'aquesta. En canvi, pel que fa al motiu pel qual la traducció no es va publicar finalment, l'estudiós argumenta que possiblement es deguera als problemes financers de la casa editorial, però que la realitat és que ni tan sols la família esbrinaren mai el perquè.
} 
(2007 i 2008), ja de jove va començar a realitzar col-laboracions literàries al diari local i al diari de Valls ${ }^{3}$. Als vint anys es va llicenciar en Dret i es va establir a Barcelona, on treballava com a secretari del Col-legi Oficial d'Arquitectes de Catalunya i Balears i com a assessor jurídic de la Càmera Oficial d’Indústria de Barcelona. Ara bé, al mateix temps, continuava col-laborant en diferents mitjans de la premsa catalana i escrivia poesia i obres de teatre en català ${ }^{4}$. A l'inici de la Guerra Civil es va exiliar a França i tornà a Madrid el 1941 on s'instal-là. En la dècada de 1950 a 1960, Vidal i Jové va recuperar la seua activitat literària anterior i va tornar a col-laborar en un gran nombre de periòdics, va escriure prefacis per a diferents treballs i va traduir una gran varietat d'obres, generalment del català i del francès al castellà, tal i com ja hem comentat anteriorment. Així, entre els francesos, va traduir al castellà l'obra d'autors com Arthur Rimbaud, Honoré de Balzac, Émile Zola, el marquès de Sade o François Rabelais; entre els catalans, a la dècada dels setanta, es va dedicar a la traducció d'obres com Narracions de Salvador Espriu, la Crònica de Ramon Muntaner, El nàufrag feliç de Ramon Folch i Camarasa, Els vençuts de Xavier Benguerel o tota l'Obra poètica de Joan Maragall, a més de les novel-les de Rodoreda ja citades ${ }^{5}$. Ara bé, si va destacar per una traducció del català al castellà va ser per traduir al castellà contemporani el Tirant lo Blanch l'any 1969 per a l'editorial Alianza i amb un pròleg de Mario Vargas Llosa. Finalment, també volem destacar dues dades significatives: el fet que el 1957 va ser finalista del Premi Joan Martorell i que el 1970 va publicar l'obra Històries del meu temps, una novel-la de tall autobiogràfic.

Podem afirmar, per tant, que ens trobem davant d'un intel·lectual català, un home que, al llarg de la seua vida, va conrear els més diversos camps de la literatura: la dramatúrgia, la poesia, la narrativa, la traducció i la producció incansable d’articles en premsa, de pròlegs i prefacis, tot i que tota aquesta producció, a dia d'avui, encara no ha rebut tot el reconeixement que es mereix ${ }^{6}$. Ara bé, també és cert que,

\footnotetext{
${ }^{3}$ Un dels seus relats de joventut va ser Per les donzelles de color de rosa publicat el 1919 a $L a$ Novel.la Nova de Barcelona.

${ }^{4}$ J. F. Vidal Jové va conrear la poesia en els anys 20 on va presentar als Jocs Florals de Barcelona les obres Tríptic de suau amor i Monjoia, aquest últim guardonat amb el Premi Extraordinari dels Mantenidors. Entre les seues obres teatrals podem trobar títols com La senyoreta Oest, Mercuri i els metges o L'oreig entre columnes. La Senyoreta Oest es va estrenar en el Teatre Poliorama de Barcelona el 1934 i va ser finalista del Premi Ignasi Iglésies concedit per la Generalitat de Catalunya per a obres teatrals en català. Mercuri i els metges es va estrenar el 6 de desembre de 1934 al Teatre Coliseu Pompeia de Barcelona. L'oreig entre columnes es va estrenar el 16 de maig de 1936 en el Teatre Orfeo Gracienc de Barcelona. També va escriure el llibret de l'òpera El estudiante de Salamanca que fou interpretada al Liceu per Hipòlit Làzaro.

${ }^{5}$ L'única referència significativa que hem trobat sobre la traducció al castellà de Jardí vora el mar a l'epistolari publicat entre Rodoreda i Sales fa referència al canvi d'editorial (d'Edhasa a Planeta) per a dur a terme la publicació. Concretament, la carta és del 12 de desembre del 1972 (quasi tres anys abans de la publicació definitiva per Planeta) i Sales s’adreça a Rodoreda en els següents termes:

Ja he anat a Planeta [...] i he parlat amb en Lara, que no veu cap inconvenient, m'ha dit a publicar l'edició castellana del Jardí vora el mar sempre i quan sigueu vós, i no ell, qui s'encari amb Edhasa, perquè no hi vol tenir conflictes. Els hauríeu d'escriure demanant-los que, en vista que han passat dos anys sense que ells hagin procedit a l'edició, us retornin el seu exemplar del contracte d'edició i donin aquest per anul·lat. [...] Si vós feu això, diu en Lara que llançarà l'edició (RODOREDA/SALES 2008; p.484-485).

${ }^{6}$ El primer a adonar-se de l'escassa atenció que Joan Francesc Vidal i Jové havia rebut per part de la crítica especialitzada va ser Alberto Lázaro quan afirmà: "El enorme caudal de traducciones, artículos, prólogos y obras de creación revelan una vida de continuo trabajo en el campo de las letras que pocas veces se vio reconocido por la crítica o el público lector” (LÁZARO, 2007, p.164).
} 
l'existència d'un major o menor reconeixement no condiciona el bagatge que Vidal i Jové posseïa quan, el 1975, publicà la traducció de Jardí vora el mar. Donat el caràcter col-loquial esmentat del model de llengua emprat a la novel-la, el fet de traduir-la, estem segurs que no li va suposar una tasca fàcil, tot i que, possiblement, el domini absolut de les dues llengües i una carrera llarga en el món de les lletres li foren de gran ajuda. Després de la lectura de l’original i de la traducció al castellà de Vidal i Jové, podem afirmar que Rodoreda va saber utilitzar-hi el llenguatge d'una manera magistral i Vidal i Jové va cercar la manera de captar-ne l'ús i es va preocupar per trobar la millor solució en la llengua veïna. És el moment ara de veure el per què d'aquesta afirmació, a partir de l'anàlisi de l'ús que Rodoreda hi fa de les unitats fraseològiques i de com el traductor va saber captar, o no, l'essència d'aquestes.

\section{Les unitats fraseològiques a Jardí vora el mar i la les variacions de la traducció castellana}

Mercè Rodoreda, en una carta adreçada a Sales el 26 de gener de 1967, afirma: "Jo tinc la impressió que serà un èxit de públic. És una novel·la carregada de diàleg: o sigui, fàcil de llegir "” (RODOREDA/SALES, 2008, p.321). El que per a ella és una novel-la carregada de diàleg, per a nosaltres és un domini indiscutible de la tècnica narrativa, ja que Rodoreda sap plasmar a la novel-la una gran quantitat d'aspectes de l'oralitat que no fan altra cosa que reafirmar la versemblança narrativa que, com ja hem dit, parteix d'un narrador del poble, d'un jardiner d'avançada edat amb una visió simple de la vida (PORTA, 2013, p.226) que ens conta, parcialment i amb les paraules pròpies d'un home de les seues característiques, el que ell va veure $o$ el que a ell li van contar. Així, entre aquests aspectes propis de l'oralitat que són presents a la novel·la podem destacar l'abundant presència d'onomatopeies, de verbs declaratius, de reproducció de diàlegs, de marcadors subjectius, com les interjeccions i els modalitzadors, però, sobretot, la presència d'un tret distintiu: el fet que, com ja va indicar Obiols, la novel·la "és [...] plena [...] de coses dites magníficament sense anomenar-les”, (RODOREDA/SALES 2008, p.329).

Aquest tret es pot relacionar plenament amb l'abundant presència d'unitats fraseològiques a la novel·la, ja que, al cap i a la fi, no deixen de ser una manera de dir sense anomenar. Un dels aspectes que més ens ha cridat l'atenció, en aquest sentit, és que Rodoreda, plenament coneixedora del català col·loquial i de les tècniques

\footnotetext{
${ }^{7}$ Possiblement aquesta manera amb què Rodoreda s'adreaçar-se al seu editor es dega al fet que, en diferents cartes, Sales valora Jardí vora el mar per darrere de la resta de novel·les publicades per l'autora, sobretot, molt per darrere de La plaça del Diamant. Especialment significativa en aquest sentit és la citació que tot seguit introduïm, extreta de la carta que Sales adreça a Rodoreda el 18 de gener de 1967: "No cal que patiu, és una molt bona novel-la. Boníssima, si no fos de la Rodoreda; vull dir sense la fâcheuse propensió que sempre tindrem de comparar tot el que escrigueu amb la Plaça. ‘Tota comparació és odiosa', i en aquest cas enfadosa per vós” (RODOREDA/SALES, 2008, p.317).

${ }^{8}$ Rodoreda, en una carta enviada a Sales el 6 de febrer de 1967, copia un fragment d'una carta que Obiols li ha enviat recentment i on li expressa la seua opinió sobre Jardí vora el mar. Segons Montserrat Casals, editora de l'epistolari, aquesta carta seria enviada per Obiols a Rodoreda l'1 de febrer de 1967. En canvi, a l'epistolari entre Obiols i Rodoreda (2010: 372-374), la carta que Obiols envia a Rodoreda en aquesta data no fa cap referència a les paraules que Rodoreda copia, és més, les referències a Jardí vora el mar són escasses i Obiols se centra, sobretot, en Mirall Trencat. També és cert que la carta no està signada, cosa molt estranya en comparació amb la resta de l'epistolari, i, per tant, podríem pensar que hi ha una part de la carta que s’ha perdut o de la qual no es té constància.
} 
narratives, duu a terme un mecanisme totalment fructífer a l'hora d'aportar versemblança. Aquest mecanisme consisteix en el fet que el narrador, al llarg del discurs, repeteix certes unitats fraseològiques o parts d'aquestes, cosa que serveix per reforçar en el lector la idea inconscient que, en tot moment, és el mateix narrador qui ens està contant la història. Així, d'una banda, algunes de les unitats que es repeteixen totalment són: ple com un ou (p.181 i 192), fer comèdia (p.39 i 169), deixar córrer (p.35 i 185) o prendre el pèl (p.41 i 121). De l'altra, trobem unitats que repeteixen certs elements lèxics com ara: sense badar boca (p.12 i 153) i ser una cosa de badar boca (p.37); com un dimoni (p.15 i 69) i de mil dimonis (p.48); agafar una mona com una casa (p.69) i agafar mones (p.190) o encarcarat com un espàrrec i (p.113) encarcarat com un filferro (p.141).

De la mateixa manera, considerem que l'autora amb el mateix objectiu de cercar la versemblança narratològica, utilitza constantment unitats fraseològiques basades en la comparació. Com que l'enumeració d'aquestes podria fer-se eterna i com que les tractarem, al llarg d'aquest article, relacionades amb altres fenòmens observats, ens limitarem a citar-ne alguns exemples: enganxar-se a algú com un poll (p.127), solitari com un plat de postres (p.113), nedar com una anguila (p.164), ser vell com l'anar a peu (p.15) o callar com una rata (p.139).

Ara bé, què hi fa Vidal i Jové a l'hora d'enfrontar-se a aquests aspectes observats? L'anàlisi comparativa ens porta a afirmar que si bé, d'una banda, respecta l'abundància de comparacions, de l'altra, de vegades, no té en compte el mecanisme de repetició d'unitats observat en la novel·la en llengua d'origen. Així, pel que fa a la traducció de les comparacions que abans hem utilitzat d'exemple, trobem pel mateix ordre: agarrarse a alguien como un piojo (p.158), solitario como un plato de postres (p.140), nadar como una anguila (p.204), ser más viejo que el tiempo (p.15) i callar como una rata (p.173). Quant al mecanisme de repetició, basant-nos en els exemples anteriors, trobem les alteracions següents que ens porten a pensar que quan repeteix la unitat no ho fa de manera intencionada:

- Ple com un ou = lleno a rebosar (p.227) i lleno que no cabía un alfiler (p.240)

- Deixar córrer = dejar correr (p.41) i no decidirse (p.232)

- Com un dimoni = de todos los demonios (p.15) i como un diablo (p.84)

- Agafar una mona i agafar mones = coger una turca (p.85) i coger pítimes (p.237)

Ara bé, també cal comentar que hem detectat que, en altres contextos on Rodoreda no havia duplicat una unitat fraseològica, Vidal i Jové sí que duplica una altra ja existent, amb la qual cosa podríem pensar que aplica certs mecanismes de compensació. Així, on Rodoreda introdueix la unitat mirar prim (p.133), Vidal i Jové la tradueix per buscar tres pies al gato (p.165), unitat que torna a aparèixer més endavant (p.175).

L'últim aspecte que volem comentar sobre el tractament que Mercè Rodoreda dóna a les unitats fraseològiques a la novel·la és el fet que l'autora no les utilitza com un tot tancat, sinó que, en certes ocasions, les modifica formalment o introdueix sintagmes amb forma d'unitat fraseològica que, en realitat, no ho són. Aquest aspecte rodoredià, inevitablement, hagué de complicar la tasca traductora de Vidal i Jové. Pel que fa a les modificacions formals trobem exemples com l'omissió del verb en la unitat ser una cosa de badar boca (p.37) traduïda com a ser una cosa de quedarse con la boca abierta (p.43) o l'existència d'unitats poc prototípiques com: costar tres rovells d'ou (p.107) traduïda com a costar un riñón (p.132) o dolç com un 
raïm (p.110) traduïda com a dulce como la uva (p.136). Quant a la invenció d'unitats per part de l'autora, el cas més cridaner és el de la unitat semblar un sarau de dàlies (p.68) que, Vidal i Jové tradueix magníficament per armarse la marimorena (p.83).

La complicació que aquest tractament de les unitats fraseològiques pogué comportar al traductor queda palesada en una carta que Vidal i Jové envia a Rodoreda el 29 de març de 1971 quan està en ple procés de traducció de Jardí vora el mar ${ }^{9}$. En aquesta carta, Vidal i Jové demanava a Rodoreda si l'autora podia aclarir-li i dir-li la traducció al castellà de certes flors, ja que no trobava, a Madrid, cap jardiner que sabera català i, en conseqüència, li puguera dir el nom en castellà d'aquestes. Al final de la carta, Vidal i Jové anota un llistat de set paraules, de les quals sols tres són referides a flors i, entre les quals, trobem, precisament, la unitat sarau de dàlies ${ }^{10}$. Com hem dit, Vidal i Jové tradueix, magistralment, aquesta unitat per armarse la marimorena. Ara bé, com que no hi ha constància de la carta que Rodoreda li envia com a contestació, no podem saber qui és el responsable de la traducció d'aquesta unitat. L’única cosa que sabem és que, en una carta posterior, del 22 d'abril de 1971, Vidal i Jové contesta a Rodoreda en els següents termes: "Molt agraït per les seves aclaracions sobre el nom d'algunes plantes que li demanava", encara que, com hem comentat, no totes les traduccions que demanava a l'autora eren referides al nom de flors.

Una vegada esmentats els mecanismes que Rodoreda empra pel que fa al tractament de les unitats fraseològiques a la novel-la i el seguiment o no per part de Vidal i Jové a la traducció d’aquesta, considerem que la forma més productiva de dur a terme la nostra anàlisi serà centrant-nos pròpiament en les solucions que Vidal i Jové cerca per a les unitats fraseològiques, a partir dels paràmetres d'equivalència, equivalència parcial i inequivalència. Com indica Gloria Corpas "la identificación de UF en TO no siempre es fácil, especialmente si el traductor no posee la competencia fraseológica adecuada en la lengua origen (LO)” (CORPAS, 2000, p.130). Aquest pressuposem que no era el cas de Vidal i Jové i la traducció de Jardí vora el mar, ja que, a més de ser un traductor professional i de tractar-se de llengües molt properes, era plenament competent tant en la llengua origen com en la llengua meta. Ara bé, "les diverses llengües tenen estructures diferents. Més, com més remotes. Però en les pròximes també hi ha dubtes” (MALLAFRÈ, 2010, p.78). És en eixos dubtes existents en la traducció d'unitats fraseològiques entre llengües properes i en les solucions adoptades en el que volem aprofundir ara. Iniciem doncs l'anàlisi per esmentar alguns dels casos en què l'equivalència entre les unitats fraseològiques és total i Vidal i Jové es limita a palesar-ho. A tall d'exemple, amb aquestes característiques podem trobar unitats fraseològiques com:

- Costar un ull de la cara (p.198) = costar un ojo de la cara (p.248)

- dormir com un liró (p.36) = dormir como un lirón (p.42)

- Ser un tros de pa (p.15) = ser un pedazo de pan (p.15)

- Sense to ni so (p.149) = sin ton ni son (p.185)

- Buscar tres peus al gat (p.140) = buscar tres pies al gato (p.175)

\footnotetext{
${ }^{9}$ A aquesta carta he pogut tenir accés gràcies a la professora Teresa Iribarren qui em va posar en contacte amb Assumpció Cheyne, la filla de Joan Francesc Vidal i Jové. Va ser ella qui, amablement, em va informar de l'existència, a la Fundació Mercè Rodoreda, d'unes cartes on Vidal i Jové preguntava certs aspectes de la traducció de Jardí vora el mar a Mercè Rodoreda.

10 Vidal i Jové demana a Rodoreda l'aclariment i traducció de baldirons, carolines, llopins, muscariraïm, sarau de dàlies, santa barricada i geranis catleia.
} 
- Anar al gra (p.156) = ir al grano (p.194)

- Punxar i no treure ni una gota de sang (p.169) = pinchar y no sacar ni una gota de sangre (p.211)

Dins d'aquest mateix grup volem fer constar un llistat d'exemples que demostren com Vidal i Jové es va enfrontar a la traducció de les unitats fraseològiques d'una manera poc seguidista, triant, de vegades, una solució que no seria l'esperable. Així, en certes ocasions, tot i que existeix un equivalent total de la unitat fraseològica en la llengua meta, ell cerca una solució que, encara que no modifica el sentit, pot fer desaparèixer la unitat fraseològica. Els exemples per especificar la presència d'aquest aspecte són:

- (Té salut) per a dar i per a vendre (p.120) = está usted hecho un muchacho (p.149), en lloc de (tiene salud) para dar i vender

- Fer esses (p.165) = ir medio borracho (p.205), en lloc de hacer eses

- Estar pet (p.70) = amonarse (p.86), en lloc d'estar pedo

- Posar-se a tret (p.85) = ponerse al alcance (p.104), en lloc de ponerse a tiro

- Fer nas (p.44) = hacer el zascandil (p.53), en lloc de meter las narices

Endinsem-nos ara en el camp de la inequivalència i, concretament, en les solucions que Vidal i Jové cerca davant la inexistència en castellà de les unitats fraseològiques emprades per Rodoreda. L'exemple més clar d'una unitat fraseològica emprada per Rodoreda sense equivalent en castellà és la unitat alt com un Sant Pau (p.168), ja que l'origen d'aquesta cal cercar-lo en una raó sociocultural i religiosa pròpiament catalana. Aquesta unitat significa ser d'una gran estatura i es va forjar arran d'una antiga festa popular que es feia el dia de la conversió de Sant Pau, a la zona de l'església barcelonina de Sant Pau del Camp, en la qual un home, que calia que fóra d'una corpulència considerable, disfressat del Sant havia de brandir una espasa enorme (ALSIUS, 1998, p.222). Vidal i Jové, davant la inexistència d'un equivalent, tradueix aquesta unitat per alto como un gigantón (p.210). D’aquesta manera, opta per parafrasejar el contingut semàntic i pragmàtic, tot i que això supose la pèrdua de la unitat fraseològica.

Una altra unitat fraseològica emprada per l'autora amb característiques semblants a l'anterior és un a Sant Pere i l'altre a Sant Pau (p.206) que Vidal i Jové tradueix per uno aquí y el otro en la luna (p.258), de manera que torna a utilitzar la paràfrasi del contingut semàntic i pragmàtic com a solució. La inequivalència en aquest cas és fruit de les referències toponímiques de la unitat fraseològica en la llengua d'origen. Ara bé, també és cert que el traductor, hàbilment, cerca estratègies per compensar aquesta pèrdua fraseològica de caràcter més nostrat. Així, Vidal i Jové tradueix la unitat emprada per Rodoreda viure a la lluna (p.170) per vivir en las Batuecas (p.213), tot i que podria haver-la traduït per estar en la luna o vivir en la luna, ja que el significat d'aquesta locució, tant en català com en castellà, és el mateix: estar molt distret. De tota manera, com hem dit, la traducció de la unitat per vivir a las Batuecas compensa el caràcter toponímic que no havia pogut recollir en la traducció d'altres unitats com un a Sant Pere i l'altre a Sant Pau, a la vegada que manté totalment el significat, ja que l'origen d'aquesta unitat fraseològica del castellà cal cercar-lo en Las Batuecas, una vall de Salamanca, un lloc apartat que fins el s. XIX era conegut com un lloc ignorant o primitiu. 
A continuació, aprofundim en el camp de l'equivalència parcial on analitzarem diferents exemples d'unitats fraseològiques a partir de paràmetres semàntics i pragmàtics. Pel que fa als paràmetres semàntics, en primer lloc, volem fer especial esment d'una unitat fraseològica emprada per Rodoreda l'origen de la qual també respon a motius socioculturals pròpiament catalans. Aquesta unitat és semblar a can seixanta (p.137). En concret, aquesta parteix d'una fàbrica de tèxtil del carrer Riereta de Barcelona caracteritzada pel desordre i la desorganització del seu amo. Pel que fa al motiu de l'atribució del mot seixanta a l'amo d'aquesta fàbrica, existeixen múltiples interpretacions; entre elles, el fet que, abans de tenir la fàbrica, s'entossudia a vendre les cebes a seixanta cèntims de pesseta, que presumia de tenir seixanta fills o perquè els seixanta obrers de la fàbrica feien cadascú l'horari que volien i no hi havia cap ordre ni concert en els afers laborals. Siga quina siga la interpretació, el que és evident és que tornem a trobar-nos davant d'una unitat catalana que complica la traducció a Vidal i Jové. En aquest cas, el traductor opta per traduir aquesta unitat per parecer la casa de tócame Roque (p.171), amb la qual cosa tria el mecanisme de la substitució. D'aquesta manera, tot i que es tracta d'una unitat que, pel seu caràcter cultural, ens podria portar a pensar que no existieix un equivalent en castellà, Vidal i Jové aconsegueix que es mantinga la unitat fraseològica sense modificar-ne el sentit, a partir del fet de cercar un referent cultural semblant en la llengua meta.

Altres exemples extrets de la traducció de la novel-la que, pels diferents paràmetres semàntics: significat fraseològic, imatge base o composició lèxica (CORPAS, 2000, 117), considerem que presenten equivalència parcial són:

- $\quad$ Curt de gambals (p.149) = corto de alcances (p.185)

- Ple com un ou (p.181 i 192) = lleno que no cabía un alfiler (p.220 i 240)

- Què sap el gat de fer culleres (p.128) = zapatero a tus zapatos (p.160)

- Costar tres rovells d'ou (p.107) = costar un riñón (p.132)

- Posar paranys (p.13) = parar trampas (p.12)

- Fer una com un cove (p.44) = hacer un pan como unas hostias (p.53)

- Anar amb orgues (p.111) = ir con cuentos (p.137)

- Encarcarat com un espàrrec (p.113) = tieso como un huso (p.140)

- Quedar-se a la lluna de València (p.116) = quedarse compuesto y sin novia (p.144)

- Més viu que la tinya (p.140) = más listo que el hambre (p.175)

- D’on surten les misses (p.204) = aflojar la mosca (p.256)

- Més eixerit que un pèsol (p.205) = más contento que unas castañuelas (p.257)

- Treure foc pels queixals (p.16) = echar chispas (p.17)

- Cargolar els budells (p.58) = retorcer las entrañas (p.71)

- Vermell com un perdigot (p.190) = colorado como un pimiento (p.238)

- Tirar al dret (p.169) = tirar por la calle de en medio (p.211)

Quant a la presència de l'equivalència parcial per paràmetres pragmàtics, volem destacar la unitat fraseològica qui paga mana (p.161) que Vidal i Jové tradueix per quien paga manda (p.201). En aquest cas l'equivalència parcial respon al motiu de la diferent freqüència d'ús, ja que, com hem pogut extreure de les fitxes del Refranero Multilingüe del Centro Virtual Cervantes, aquest refrany és molt més utilitzat en català que en castellà. 
Finalment, per acabar l'anàlisi de la traducció de les unitats fraseològiques de Jardí vora el mar que duu a terme Vidal i Jové, volem deixar constància dels següents fenòmens observats. En primer lloc, el fet que hi ha ocasions en què Vidal $i$ Jové opta per la paràfrasi del contingut semàntic i pragmàtic de la unitat fraseològica, encara que això supose la pèrdua d'aquesta, possiblement per la dificultat que li suposa trobar-hi un equivalent. Entre aquests casos podem destacar:

- El prometre no fa pobre (p.107) = prometer no cuesta nada (p.133)

- Girar cua (p.45) = volverse (p.54)

- Fer salat (p.12) = no pitar (p.11)

- Ai al cor (p.39) = sobresalto (p.46)

- Fer (una cosa) la balança amb l'altra (p.14) = una cosa compensar la otra (p.14)

- Fer nosa (p.123) = estorbar (p.153)

- Tocar el dos (p.53) = tomar carrerilla (p.65)

- Anar de refiat (p.121) = fiarse demasiado (p.151)

- $($ Dir ) passi-ho bé (p.174) = despedirse (p.218)

- A peu pla (p.197) = a la misma altura (p.247)

En segon lloc, el fet que, també en certes ocasions, el traductor es deixa emportar per una equivalència aparent que comporta la introducció a la traducció de "falsos amigos fraseológicos" (CORPAS, 2000, 118). Alguns exemples de la presència d'aquest fenomen són: la traducció de la unitat ser joc de poques taules (p.48) per ser juego de poca monta (p.58) quan la primera, segons el DIEC, significa "ser cosa fàcil i sense complicacions" i la segona, segons el DRAE, significa "de poca importancia"; la traducció de la unitat caure del ruc (p.147) que, segons el DIEC, significa “adonar-se d'alguna cosa, deduir-la” per caer del burro (p.153) que, segons el DRAE, significa "reconocer que ha errado en algo" o la traducció de la locució d'una revolada (p.147) que segons el DIEC significa "amb un moviment ràpid i violent, com una estirada, una empenta, etc.” per la locució de un revuelo (p.183) que segons el DRAE significa "pronta y ligeramente, como de paso", de manera que es perd el matís de violència en l'acció propi de la unitat en català i que té sentit en el context de la novel·la en què apareix.

En tercer lloc i per acabar definitivament amb l'anàlisi, esmentarem certs errors en la traducció de les unitats fraseològiques de la novel·la deguts, d'una banda, a la inobservança de la presència d'aquestes en la llengua meta, cosa que comporta una traducció literal, o, de l'altra, a una interpretació incorrecta. Entre els primers, destaquem la traducció de picar els dits (a algú) (p.23) que, segons el DIEC, significa "escarmentar-lo" per dar en los nudillos (p.25) o la traducció d'un bé de Déu (d'alguna cosa)” (p.172) per una bendición (de algo) (p.215) quan, segons el DIEC, un bé de Déu és una "expressió usada per a ponderar l'abundor i l'excel·lència d'alguna cosa”, sentit que no posseeix la paraula bendición del castellà. Dels segons, volem comentar la traducció de la unitat haver-n’hi per llogar-hi cadires (p.204) per no ser nada del otro mundo (p.256), ja que la unitat fraseològica en català, segons el DIEC, és una “expressió per a ponderar com és de curiós, d'increïble, d'inaudit quelcom” i la traducció que hi dóna Vidal i Jové, significa, inexplicablement, tot el contrari. 


\section{Conclusions}

Tal i com indicàvem en la Introducció d'aquest article, el nostre objectiu principal era comprovar quina havia estat la variació fraseològica duta a terme en la traducció de Jardí vora el mar i col·laborar, així, en la creació de diferents diccionaris fraseològics de diferents autors catalans defensada per Károly Morvay. De la mateixa manera, hem intentat dur a terme un treball descriptiu i empíric on es contrastaren les unitats fraseològiques del text original amb les del text meta, un tipus d'anàlisi considerat molt fructífer per a la pedagogia de la traducció (CORPAD, 2000, p.132). L'assoliment d'aquest objectiu, per tant, s'ha basat en una anàlisi contrastada de les unitats fraseològiques, a partir dels criteris d'equivalència total, equivalència parcial i inequivalència que ens ha permès:

1. Extreure els diferents mecanismes (compensació, substitució i paràfrasi del contingut semàntic i pragmàtic) utilitzats per Vidal i Jové a l'hora d'enfrontar-se a la dificultat de traducció que presentaven diverses unitats fraseològiques emprades per Rodoreda.

2. Constatar la dificultat de traducció de les unitats fraseològiques entre llengües tan properes com l'espanyol i el català a partir dels exemples d'inequivalència i de les inobservances comeses pel traductor.

3. Descobrir que tant l'autora com el traductor posseïen una concepció similar a l'hora d'emprar la fraseologia en una novel-la: el fet que aquesta ha de semblar, per damunt de tot natural, poc forçada, per a la qual cosa no s'ha d'entendre com un tot tancat, sinó com unes unitats amb les quals jugar, amb les quals dir sense dir.

A més, a partir de l'anàlisi realitzada en aquest treball, hem intentat, d'una banda, acostar-nos una mica més a la gran capacitat narratològica i a l'immens domini de la llengua que posseïa Mercè Rodoreda i, tot això, des d'una perspectiva que, fins ara, no havia estat analitzada d'una manera específica: el tractament que l'autora dóna a la fraseologia a les seues novel·les. De l'altra, hem volgut redescobrir o descobrir, com és el nostre cas, el traductor Joan Francesc Vidal i Jové que, en paraules d'una dels seus millors estudiosos, "era un traductor dotat d'un extraordinari sentit de la llengua que sempre prioritzà l'expressió més genuïna i la llegibilitat” (IRIBARREN, 2011, p.92).

Trinidad Escudero Alcamí

triniescuderoalcami@gmail.com

Becària de lexicografia i terminologia de l'Acadèmia Valenciana de la Llengua

Universitat de València

\section{Referències bibliogràfiques}

Alsıus, Salvador. Hem perdut l'oremus. Petita enciclopèdia de la cultura catòlica. Barcelona: La Campana, 1998. 312p. 
ARnAU, Carme. Introducció a la narrativa de Mercè Rodoreda. El mite de la infantesa. Barcelona: Edicions 62, 1979, 315p.

SEVILLA, Julia, Zurdo, M, ${ }^{\mathrm{a}}$ I. Teresa [dir.]. Refranero multilingüe. Madrid: Instituto Cervantes (Centro Virtual Cervantes), 2009. Disponible en: http://cvc.cervantes.es/lengua/refranero/ficha.aspx?Par=59451\&Lng=0.

Última consulta: 18 set. 2014

CORPAS, Gloria. Fraseología y traducción. En: Adolf PiQuer, Vicent SAlvador (eds.). El discurs prefabricat. Estudis de fraseologia teòrica $i$ aplicada. Castelló: Publicacions de la Universitat Jaume I, 2000, 421p.

Institut D’estudis Catalans. Diccionari de la llengua catalana. Barcelona: Institut d'Estudis Catalans, 1997. Disponible en: http://dlc.iec.cat/. Última consulta: 20 set. 2014

Real Academia Española. Diccionario de la lengua espanyola. Madrid: Real Academia Española, 2001. Disponible en: http://www.rae.es/recursos/diccionarios/drae. Última consulta: 28 set. 2014

Iribarren, Teresa. VidAL i Jové, Joan Francesc. En: MontSERRAt BaCARdí, Pilar Godoy (coord.). Diccionari de la traducció catalana. Vic: Eumo Editorial, Universitat Autònoma de Barcelona, Universitat de les Illes Balears, Universitat Jaume I \& Universitat de Vic, 2011, p.581.

IRIBARREN, Teresa. La primera traducció catalana de l'Ulisses (1966) de James Joyce, de Joan Francesc Vidal Jové. En: Sílvia Collvinent, Cornèlia Eisner i Enric GALlÉN (ed.). La traducció i el món editorial català de postguerra. III Simposi sobre traducció i recepció en la literatura catalana contemporània. Lleida: Punctum \& Trilcat, p.81-94, 2011.

LÁZARO, Alberto. El misterio del primer Ulysses catalán: la odisea de Joan Francesc Vidal Jové. En: Santiago J. HenríQuez, Carmen MARTín (coord.). Estudios Joyceanos en Gran Canaria: Joyce in his palms. Madrid: Huerga y Fierro editores, p.159-173, 2007.

. The History of the First Catalan Ulysses, by J. F. Vidal Jové. En: Papers of Joyce, núm. 14, p.51-69, 2008.

MALlAfRÈ, Joaquim. Les traduccions de l'obra de Mercè Rodoreda. En: Joaquim Molas (ed.). Congrés Internacional Mercè Rodoreda. Actes, Barcelona 1-5 d'octubre de 2008. Barcelona: Sociedad Estatal de Conmemoraciones Culturales/Institut d’Estudis Catalans/Fundació Mercè Rodoreda, 2010. p. 6981.

Mencos, Maria Isidra. Mercè Rodoreda: una bibliografia crítica (1963-2001). Barcelona: Fundació Mercè Rodoreda, 2003. 111p.

MoRvAY, Károly. La fraseologia en la llengua literària del segle xx. En: Actes del Tretzè Col·loqui Internacional de Llengua i Literatura Catalanes. Barcelona: Publicacions de l'Abadia de Montserrat, 2006. p. 387-412.

OBIols, Armand.; SAludes, Anna Maria. (ed.) Cartes a Mercè Rodoreda. Barcelona: Fundació la Mirada, 2010. 408p.

PorTA, Roser. Molt més que la novel-lista de les flors. En: Mercè Rodoreda. Jardí vora el mar. Barcelona: Club Editor Jove, 2013. p. 215-238.

RODOREDA, Mercè. Jardí vora el mar. Barcelona: Club Editor Jove, 2013.

. Jardín junto al mar. Traducció al castellà de J. F. Vidal Jové. Barcelona: Planeta, 1975.

Rodoreda, Mercè/Sales, Joan.; Montserrat Casals (ed.). Cartes completes: 19601983. Mercè Rodoreda, Joan Sales. Barcelona: Club Editor, 2008. 1101p. 